\title{
Substantiation of Parameters and Operating Modes for the Bunch Planting Device of the Pneumatic Seeder
}

\author{
Ivan A. Kravchenko*, Ivan N. Krasnov, Aleksandr A. Potseluev, \\ Vladimir D. SIDOROV
}

\begin{abstract}
The purpose of this work is to develop a dosing system that provides highquality bunch planting of watermelon seeds with a given seeding rate and their uniform distribution over the plant nutrition area. It is important to know how many seeds it is needed in the bunch in order to provide the required number of plants in a certain plant nutrition area. The method to achieve this goal is to determine the optimal operating modes for the seeding device, in which the dosing system would supply the seed to the bunch without gaps, searching for dependencies that can determine the required number of the sown seeds in the bunch, taking into account their germination and the number of plants specified by agrotechnical conditions in every bunch. Based on the obtained dependencies, determining the probability of bunches with various numbers of plants, while sowing four seeds in the seedbed with maximum field germination, the design of experimental seed discs is proposed, allowing bunch planting and germination due to easy destruction of the soil crust. At the same time, optimal use of the nutritional area for plants, and, consequently, an increase in the yield of the sown crops is ensured. Experimental seed discs with a group arrangement of suction holes (four cells each) will provide bunch planting of watermelon seeds in accordance with agrotechnical requirements.
\end{abstract}

Keywords: seeds, bunch planting, dosing systems, germination probability, seeds and plants distribution

\footnotetext{
*Corresponding author. E-mail address: ivan.kravchenko@mail.ru

Department of Technology and Mechanization of Agriculture, Azov-Black Sea Engineering Institute - Branch Don State Agrarian University of Zernograd, Lenina St., 19, Zernograd, Rostov Region, 347740, Russia
} 


\section{Introduction}

One of the most common crops in many countries is watermelon (Citrullus lanatus Mansf.). The harmonious combination of sugars, mineral salts and vitamins gives the pulp of watermelon a unique taste and aroma. It is especially nice to eat fresh watermelon on a hot afternoon.

Watermelon honey - bekmez, is prepared from the pulp of the watermelon, and the rind is used to make candied fruits. There is a great medicinal value of the watermelon. A special diet to treat kidney disease, preventing the formation of gravel is developed. The watermelon in food is useful for obesity. Introduction of watermelon feed into the diet of animals increases their milk productivity. Small fruits are usually salted for future use, and some varieties can be stored up to 5-6 months after harvest.

Due to the biological diversity, the cucurbits crops are characterized by a prolonged period of germination, different growth forces and reactions to unfavorable growing conditions. As a result, plants develop unevenly, which leads to a decrease in yield.

With intensive use of land, the size and quality of the cucurbits crop depends directly on the field germination of seeds and the optimal plant density: both increased and flat density leads to a decrease in yield. Therefore, at the present stage of watermelon growing development, the high quality of sowing seeds is vital.

It was established that the existing constructions of the dosing device parts for pneumatic seeders do not ensure the high performance, appropriate for agricultural requirements for seeding the cucurbits.

The analysis results of Valyanov [1], Budagov [2], Abezin [3], Semenov [4], Lobachevsky [5], Bespamyatnova [6], Belik [7], Bondarenko [8] and other researchers have shown that to perform bunch planting of cucurbit seeds the most promising is the design-functional scheme of a pneumatic device with a group arrangement of suction holes on the disc.

In this regard, it is necessary to develop a dosing system that provides high-quality bunch planting of watermelon seeds with a given seeding rate and uniform distribution over the sown area.

At the same time, it is necessary to optimize the technological process of watermelon seeds bunch planting by a pneumatic seeder and to develop the design of group suction elements for the seeding disc taking into account the phenomena peculiar for the granular material. It is necessary to get dependencies to analyze the process of watermelon seeds bunch planting, determine the optimal parameters and modes of operation for the seeding device. fined:

In accordance with the goal, the following research tasks were de-

1. The study of the watermelon seeds technological properties. 
2. Identification of the structural and functional capabilities of the serial pneumatic seeder device in the process of watermelon seeds bunch planting.

3. Development of the physical models system, carrying out comprehensive theoretical studies of the bunch planting process on the basis of the step-by-step analysis.

4. Determination of the optimal parameters and modes for the dosing system operation, providing bunch planting of watermelon seeds.

5. Development of engineering calculation methods and creation of a pneumatic seeder device design for bunch planting of watermelon seeds.

\section{Materials and methods}

The basis for further research was the hypothesis that one of the ways to intensify and improve the quality indicators of the watermelon seeds bunch planting could be the unification of a group of cells on a seeding disc with a common suction hole located on the side of the vacuum chamber of the seeding device.

To describe the processes occurring in the active layer of seeds located in the seed chamber of the seeding device, we used the well-known model of a granular material. The particles that make up this material are absolutely solid equal balls with a certain fixed angle of laying down in the body volume of the device $[9,10]$. Let us consider the equilibrium condition of a particle sucked to the hole in the disc of a pneumatic seeder device without an agitator, assuming that the hole of the seeding disc is located at the intersection point of all forces and is blocked by the particle (Fig. 1).

The following forces will act on the attached particle:

$P$ is the force of the vertical pressure of the overlying layers, $\mathrm{N}$;

$P_{m p 1}^{1}, P_{m p 1}^{11}-$ the forces of internal friction of particles, $\mathrm{N}$;

$P_{m p 2}^{1}, P_{m p 2}^{11}-$ friction forces of particles on the surface of the seeding disc, $\mathrm{N}$;

$P_{c b}$ - centrifugal force, $\mathrm{N}$;

$m g$ - particle gravity, $\mathrm{N}$;

$T_{x}, T_{y}$ - friction forces that keep the attached particle from the detaching, $\mathrm{N}$.

As the studies have shown, the vacuum required to keep particles from detaching along the $X$ axis should be greater than the vacuum needed to keep the particles along the $Y$ axis. Therefore, we will consider the equilibrium of a particle only relative to the $X$ axis.

From the condition of particle equilibrium relating to the $X$ axis, we found the amount of vacuum required to hold the particle by the suction hole of the disc in the pneumatic device without an agitator: 


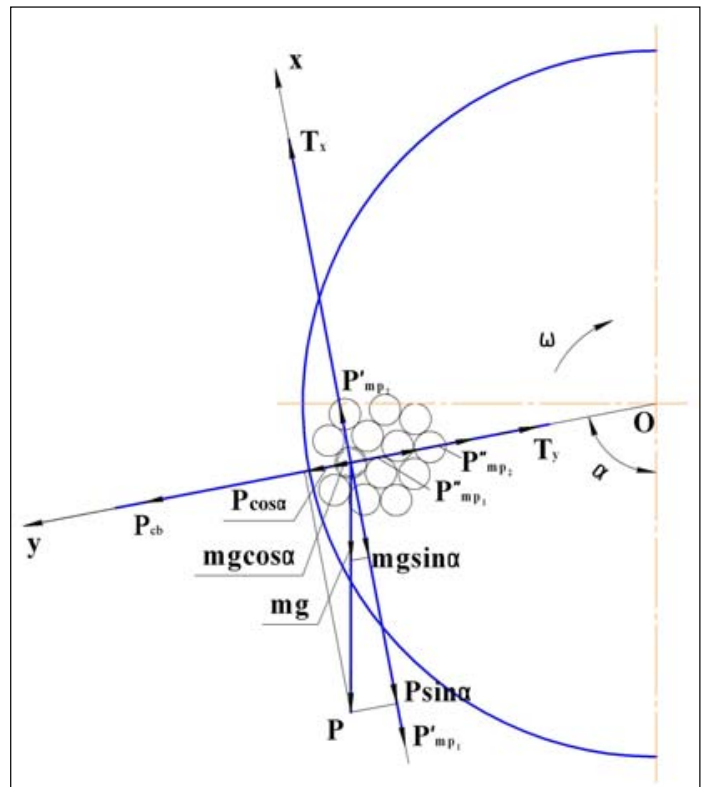

Fig. 1. Diagram of the forces acting on the particle attached to the hole of the seeding disc. $\omega$ - the angular velocity of the seeding disk, $\mathrm{s}^{-1} ; \alpha$ - the angle of the hole rotation before entering the vacuum zone, deg.

$$
\begin{aligned}
\Delta P= & \frac{N m g \sin \alpha}{f_{1} \pi d_{\text {hole }}^{2}} \\
& +\frac{N \sigma g F\left[I+f_{1} \operatorname{tg}(\beta+\psi)\right] d_{1}\left[\sin \alpha \cos \beta+\sin \beta\left(f-f_{1}\right)\right]}{f_{1}^{2} \pi d_{\text {hole }}^{2} \operatorname{tg}(\beta+\psi)},
\end{aligned}
$$

where $m$ - the mass of the particle, $\mathrm{kg} ; g$ - gravitational acceleration, $\mathrm{m} / \mathrm{s}^{2}$; $N$ - the number of suction holes on the disk; $F$ - the cross-sectional area of the particle, $\mathrm{m}^{2} ; f$ - the coefficient of internal friction of particles; $f_{1}$ - the particle coefficient of friction on the surface of the seeding disc; $\beta$ - the particle laying angle, deg.; $\psi$ - the angle of internal friction of the particles, deg.; $d_{1}$ - particle diameter, $\mathrm{m} ; d_{\text {hole }}$ - diameter of the suction hole, $\mathrm{m} ; \alpha$ - the angle of the hole rotation before entering the vacuum zone, deg.; $\rho$ - seed bulk density, $\mathrm{kg} / \mathrm{m}^{3}$.

It was established that the process of sucking the seed to the disc hole of a pneumatic seeding device is extremely important in the device operation. If during the passage of the suction hole in the active layer the seeds do not attach to it or were knocked out by other seeds, then a gap occurs that cannot be fixed during the further stages of the technological process of the device. Consequently, it is necessary to create such operating conditions for the de- 
vice so that gaps were excluded or minimized, when the hole exits the active layer [11].

The process of sucking seeds to the disc hole is significantly influenced by the following factors: the diameter of the suction hole, the magnitude of the vacuum, the seeding disc rotation frequency. There is a need to take into account the ratio between the rotational speed of the seeding disc and the peripheral speed of the seeder drive wheel. This ratio, called as a gear ratio, in turn affects the geometrical parameters of the seeding device. The gear ratio of the mechanical drive from the drive wheel of the seeder to the seeder disc can be determined by the formula:

$$
i=(k \cdot L) / D_{\text {hole }},
$$

where: $L$ - the width of interholes, $\mathrm{m}$; $D_{\text {hole }}$ - the circle diameter of the hole arrangement on the disc, $\mathrm{m} ; k$ - coefficient, reflecting the number of hole groups on the disc, $(k=4)$.

The kinematic diagram of the drive in the rotational motion of the seeding disc is represented in Fig. 2.

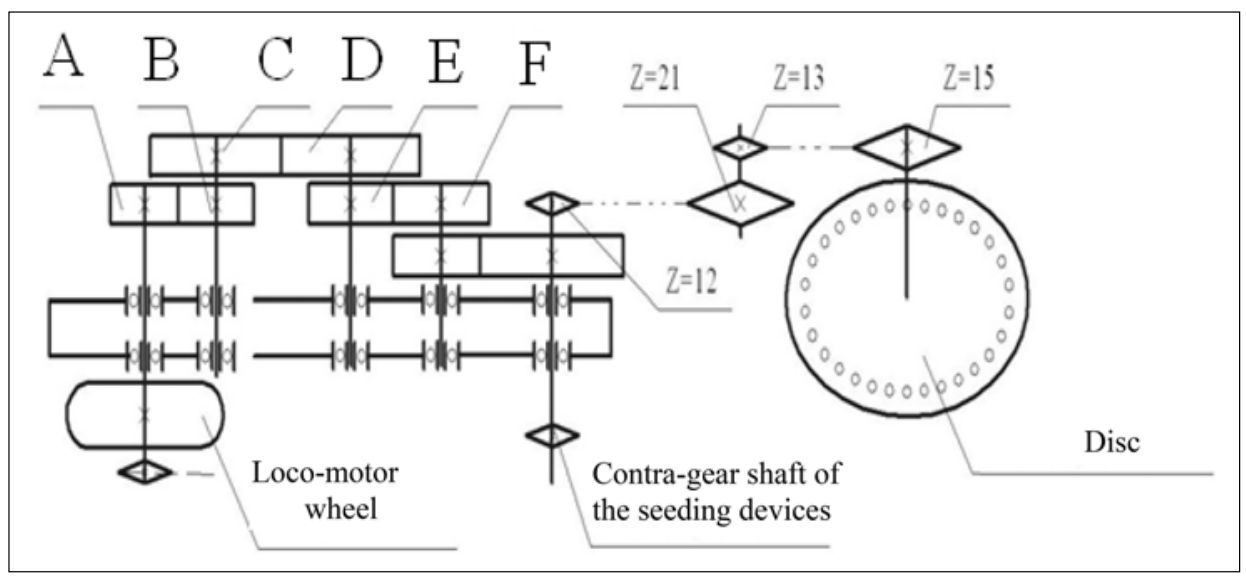

Fig. 2. Kinematic diagram of the drive mechanism of the planter

where

$\mathrm{A}$ is the gear gear $(z 26, z 25, z 21, z 20)$;

$\mathrm{B}$ - gearbox gear $(z 26, z 25, z 21, z 20)$;

C - gearbox gear $(z 25, z 35)$;

$\mathrm{D}$ - gearbox gear $(z 25, z 35)$;

$\mathrm{E}$ - gearbox gear $(z 28, z 26, z 20, z 18)$;

$\mathrm{F}$ - gearbox gear $(z 28, z 26, z 20, z 18)$.

When selecting gear pairs, the following conditions must be met: 


$$
\mathrm{A}+\mathrm{B}=46 ; \quad \mathrm{C}+\mathrm{D}=60 ; \quad \mathrm{E}+\mathrm{F}=46
$$

The suction holes diameter of the seeding disc is determined from the equation:

$$
d_{\text {s.h }}=(0.5 \ldots 0.6) b_{S}
$$

where $b_{S}$ is the seed width (average size), $\mathrm{mm}$.

Since the angular velocity of the disc:

$$
\omega=v_{\text {periph }} / \mathrm{r} \mathrm{s}^{-1},
$$

then its rotational frequency is equal to

$$
n_{\text {disc }}=30 \omega / \pi, \mathrm{rpm} \text {. }
$$

Therefore, the peripheral speed of the loco-motor wheel of the seeder should be equal to

$$
v_{\text {wheel }}=v_{\text {periph }} i \text {. }
$$

For optimal seeding conditions, the speed of the tractor with the seeder should be the same.

When creating new seeders and operating existing ones, for accurate bunch planting of arable crops the dependencies are of great importance, with which it would be possible to determine the probabilities of the plants distribution in the bunch and the number of the sown seeds, taking into account their germination.

With accurate seeding, the distribution of plants in bunches follows the binomial rule, depending on the field germination rate $[12,13]$. With ideally accurate seeding of $n$ seeds in a bunch and the field germination rate from 0 to $100 \%$, the number of plants in the bunches on the field varies from 0 to $n$.

Let us introduce the following notation: $v_{1}$ is the probability of seed germination; $v_{0}$ is the probability of seed non-germination. It is evident that

$$
v_{0}+v_{1}=1 \text {. }
$$

Basing on the theorem of the independent events probability multiplying, the distribution pattern of plants in bunches will be:

$$
\left(v_{0}+v_{1}\right)^{n}=P_{0}+P_{1}+P_{2}+\ldots+P_{n}
$$

where $P_{0}, P_{1}, P_{2}, \ldots, P_{i}, \ldots, P_{n}$ are the probabilities of plants occurrence in bunches, respectively, with $0,1,2, \ldots, i, \ldots, n$ plants in them, which corresponds to decomposition terms of the Newtonian binomial.

Then, the probability of the bunches occurrence $(P)$ with a different number of plants $(k)$ in them, when seeding $n$ seeds in a bunch with a specific field 
germination rate can be determined by the known formula of the binomial distribution [14, 15]:

$$
P_{k(n)}=\frac{n(n-1)(n-2) \cdots[n-(k-1)]}{k !} v_{0}^{n-k} v_{1}^{k} .
$$

Let us determine by the formula (9) the probability of the bunches occurrence $\left(P_{i}\right)$ with a different number of plants $(k)$ in them when seeding four $(n=4)$ seeds in a bunch with different field germination rate. Dependencies for calculating the probability of bunches with the number of plants $(k)$ in them with $(n=4)$ seeds planted into the bunch with a specific field germination rate are summarized in Table 1.

According to agrotechnical requirements for seeding the cucurbits, at least $80 \%$ of bunches with $4 \pm 1$ plants should be provided $[16,17]$. At the same time, by long-term observations it was established that the field germination of watermelon seeds ranges from $60 \%$ to $85 \%$.

Table 1. Calculated dependencies to determine the probability of bunches with various numbers of plants when four seeds are precisely sown in a bunch with a specific field germination rate

\begin{tabular}{|c|c|}
\hline $\begin{array}{l}\text { Probability of the bunches occurrence } \\
\text { with the }(k) \text { number of plants }\end{array}$ & $\begin{array}{l}\text { Formula for calculating the probabilities } \\
\text { with } n=4\end{array}$ \\
\hline$P_{0(n)}$ & $v_{0}^{4}$ \\
\hline$P_{1(n)}$ & $4 v_{0}^{3} v_{1}$ \\
\hline$P_{2(n)}$ & $6 v_{0}^{2} v_{1}^{2}$ \\
\hline$P_{3(n)}$ & $4 v_{0} v_{1}^{3}$ \\
\hline$P_{4(n)}$ & $v_{1}^{4}$ \\
\hline
\end{tabular}

Table 2. The plants distribution probability in the bunches for ideally accurate planting of four seeds in the bunch, depending on the field germination of seeds

\begin{tabular}{|l|r|r|r|c|c|c|c|c|c|c|r|r|r|}
\hline $\begin{array}{l}\text { Seeds germination } \\
(\%)\end{array}$ & 0 & 10 & 20 & 30 & 40 & 50 & 60 & 70 & 80 & 90 & 100 \\
\hline $\begin{array}{l}\text { Number of plants } \\
\text { in a bunch }\end{array}$ & \multicolumn{8}{|c|}{ Probability of bunches with $(k)$ number of plants with a specific } \\
\hline 0 & \multicolumn{8}{|c|}{ field germination of seeds } \\
\hline 1 & 100 & 65.6 & 41.00 & 24.0 & 13.0 & 6.3 & 2.6 & 0.8 & 0.16 & 0.01 & 0 \\
\hline 2 & 0 & 29.2 & 41.00 & 41.2 & 34.6 & 25.0 & 15.4 & 7.6 & 2.60 & 0.4 & 0 \\
\hline 3 & 0 & 4.9 & 15.40 & 26.5 & 34.5 & 37.5 & 34.5 & 26.5 & 15.40 & 4.9 & 0 \\
\hline 4 & 0 & 0.4 & 2.60 & 7.6 & 15.4 & 25.0 & 34.6 & 41.1 & 41.00 & 29.2 & 0 \\
\hline
\end{tabular}


The calculated values of the bunches occurrence probability with a different number of plants with precise seeding of four seeds in a bunch, depending on field germination rate, are presented in Table 2.

Based on the data in Table 2, a graph of the plants distribution probability in bunches for a particular case of ideally precise seeding of four seeds in a bunch is plotted, depending on the field germination of seeds (Fig. 3).

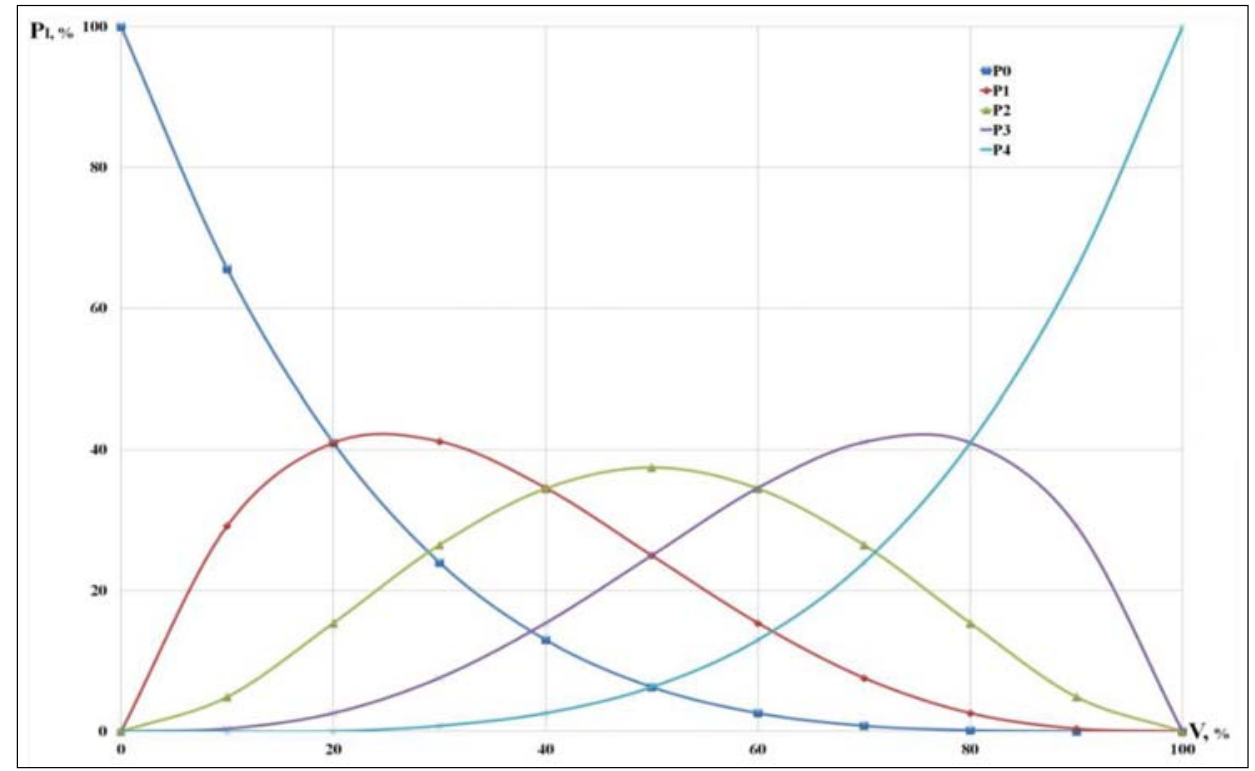

Fig. 3. Graph of the plants distribution probability in the bunches for ideally accurate planting of four seeds in the bunch, depending on the field germination of seeds. $X$ axis - field germination of seeds, $\%$; $Y$ axis - the probability of bunches with the number of plants from zero to four, $\% ; P_{0}$ - the probability of empty bunches; $P_{1}$ - the probability of bunches with one plant; $P_{2}$ - the probability of bunches with two plants; $P_{3}$ - the probabil-

ity of bunches with three plants; $P_{4}$ - the probability of bunches with four plants

Therefore, to ensure the planting of watermelon seeds in accordance with agrotechnical requirements, it is necessary to arrange sucking holes on the seeding discs in groups (four cells each), which makes it necessary to upgrade the seeding device of the pneumatic seeder SPB-8 [18].

To this end, suction and seeping holes can be placed in each disc (Fig. 4). The suction holes of the disc are located on the side of the seed chamber, and the seeping holes are on the side of the vacuum chamber. The suction holes with a diameter of $4-5 \mathrm{~mm}$, are located on the disc in groups of four holes in each group, there are four such groups on the disc. On the reverse side of the disc there are four seeping holes in the form of a circle, which unites a group of suction holes with its area. 


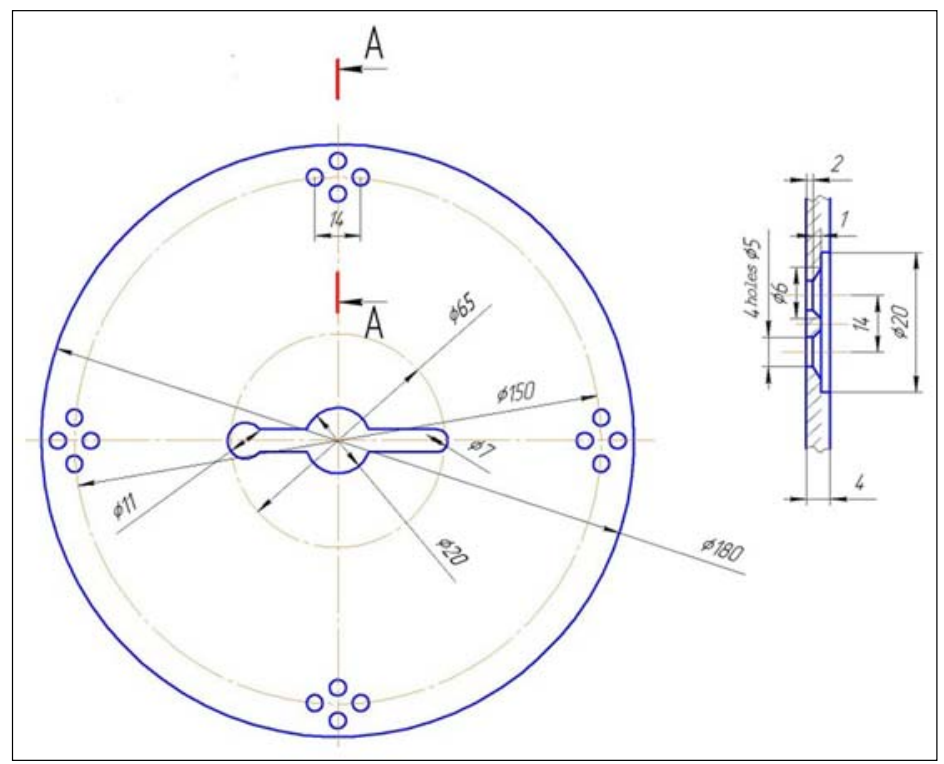

Fig. 4. Technical draw of the experimental seeding disc

The seeding device of the SPB-8 seeder works as follows [18]. The vacuum in the vacuum chamber of the seeding device is created by a centrifugal fan, driven in rotation by the PTO tractor. During the device operation, the seeds from the tanker come through the flow channel into the seed chamber of the seeding device, contacting with the cells of the seeding disc. During the rotation of the seeding disc and in the presence of the necessary vacuum in the vacuum chamber, the seeds are driven by agitator and attach to the cells that capture separate groups of seeds (by four) and carry them out of the seed chamber.

Then, the seeds remaining on the disc are transported to the cell unloading zone, where as a result of vacuum shielding and the impact of the ejector, the seeds are separated from the seeding disc in groups and fall along a definite path, corrected by the deflector, to the opener attached to the bottom of the device. Upon further movement of the cell, the dosing cycle repeats.

In order to ensure a given seeding scheme in accordance with agrotechnical requirements, it is necessary to make working settings of the seeder. The inter-row width equal to $1.4 \mathrm{~m}$ is obtained by using the $2 \mathrm{nd}, 4$ th, 6 th, and 8th seeding sections on an eight-row seeder. Seeding devices of the remaining sections of the seeder are not loaded with seeds. Inter-hole width equal to $1.4 \mathrm{~m}$ will be obtained by selecting the gear ratio from the loco-motor wheel of the seeder to the seeding disc. 


\section{Results}

Experimental studies of the improved seeding discs working process were carried out in the field.

The seeder was set up for planting watermelon seeds according to the proposed scheme. The proposed discs were installed in the seeding devices of the seeding sections numbered two, four, six and eight. Watermelon seeds were sown.

Simultaneously with the seeding, additionally, seeds were manually sown in one row between two rows in the amount of 500 pieces to determine the field germination of seeds.

Seeds for the control seeding to determine their field germination were prepared by the method of cruciform division. To do this, a sample of seeds $(1.0 \mathrm{~kg})$ was poured on the table. The seeds were thoroughly mixed and placed on the table in a thin layer in the form of a square. With the help of a ruler the square was divided diagonally into 4 parts. Two opposite parts were put together and mixed again. Division continued until a sample with 500 seeds was obtained.

The characteristics of the plants distribution in bunches after seeding with a pneumatic seeder, using experimental seeding discs are presented in Table 3. At the same time, the seeds field germination was determined after the experiment, it was $68.6 \%$.

The indicators characterizing the operation quality of the pneumatic seeding device ( $M$ is the average seed flow through suction hole, pcs; $\pm G$ is the standard deviation, pcs; $V$ is the coefficient of variation, $\%$; $\alpha$ is the experimental error, \%) were determined by the well-known formulas of mathematical statistics [19, 20].

Under field conditions, the group cells of the seeding disc, each having four suction holes, provided from 2 to 6 seeds for each bunch. Taking into account the field germination, the distribution of plants in the bunches is presented in Table 3.

To assess the quality of the seeding device operation, studying the characteristics of the plants distribution after the emergence of shoots, a method to identify the pattern of seeding by the number of shoots in the field was

Table 3. The plants distribution characteristics after sowing by seeding devices with experimental discs under the field conditions

\begin{tabular}{|l|c|c|c|c|c|c|c|c|c|c|c|}
\hline \multirow{2}{*}{$\begin{array}{l}\text { Field germi- } \\
\text { nation (\%) }\end{array}$} & \multicolumn{6}{|c|}{$\begin{array}{c}\text { Number of bunches (\%) with the number } \\
\text { of plants in them (pcs) }\end{array}$} & $\begin{array}{c}\mathrm{M} \\
(\mathrm{pcs})\end{array}$ & $\begin{array}{c} \pm G \\
(\mathrm{pcs})\end{array}$ & $\begin{array}{c}V \\
(\%)\end{array}$ & $\begin{array}{c}\alpha \\
(\%)\end{array}$ \\
\cline { 2 - 13 } & 0 & 1 & 2 & 3 & 4 & 5 & 6 & & & & \\
\hline 68.6 & 1.3 & 3.2 & 22.8 & 36.0 & 19.9 & 8.9 & 1.9 & 2.92 & 1.47 & 50.34 & 2.34 \\
\hline
\end{tabular}


Table 4. Estimated characteristics of the plants distribution in the bunches, supplying four seeds in the bunch, depending on the field germination

\begin{tabular}{|c|c|c|c|c|c|c|c|c|c|}
\hline \multirow[t]{2}{*}{$\begin{array}{l}\text { Field germi- } \\
\text { nation }(\%)\end{array}$} & \multicolumn{5}{|c|}{$\begin{array}{l}\text { Estimated number of bunches (\%) with } \\
\text { the number of plants in them (pcs) }\end{array}$} & \multirow[t]{2}{*}{$\begin{array}{c}M \\
\text { (pcs) }\end{array}$} & \multirow[t]{2}{*}{$\begin{array}{c} \pm G \\
\text { (pcs) }\end{array}$} & \multirow[t]{2}{*}{$\begin{array}{c}V \\
(\%)\end{array}$} & \multirow[t]{2}{*}{$\begin{array}{c}\alpha \\
(\%)\end{array}$} \\
\hline & 0 & 1 & 2 & 3 & 4 & & & & \\
\hline 68.6 & 0.8 & 6.8 & 26.5 & 41.1 & 24.0 & 3.15 & 1.52 & 48.25 & 1.41 \\
\hline
\end{tabular}

used. $[5,13]$. Estimated characteristics of the plants distribution in the bunches, when sowing four seeds in a bunch, and their field germination (68.6\%) are summarized in Table 4.

Variation curves of the plants distribution in the bunches with the seeds field germination of $68.6 \%$, obtained from field trials after the bunch planting with experimental seeding discs and with the theoretical calculations results of supplying four seeds to the bunch, are presented in Fig. 5.

The analysis of Fig. 5 suggests that a pneumatic seeding device with experimental seeding discs provides the bunch planting of cucurbits in field conditions with close to theoretically possible characteristics for this process. Not large deviations from the theoretically possible number of plants in a bunch can be attributed to a series of other factors that occur during the cultivation of cucurbits.

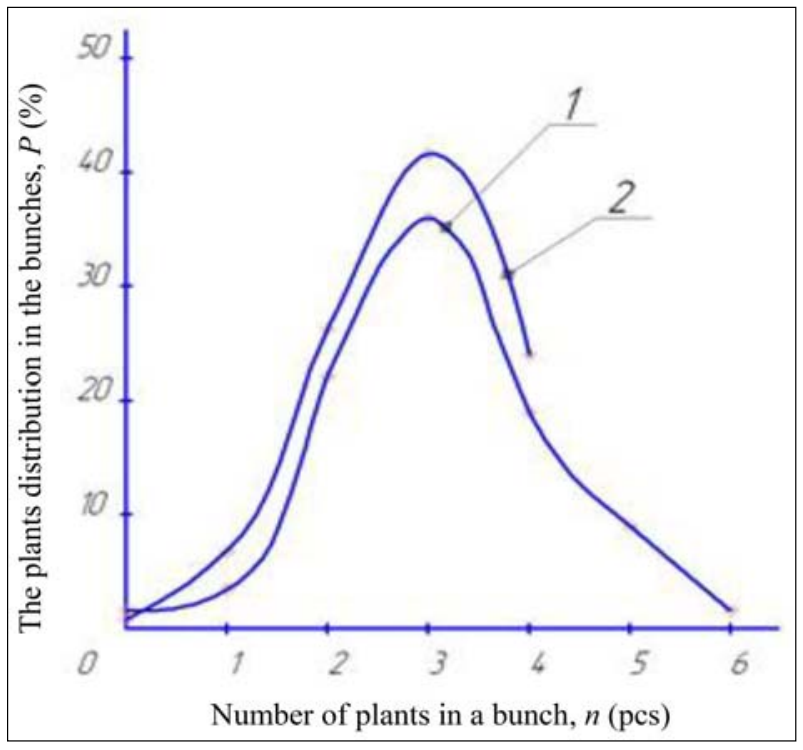

Fig. 5. Variation curves of the plants distribution in the bunches in field conditions (curve 1) and the theoretical calculations for the bunch planting with field germination $68.6 \%$ (curve 2 ) 


\section{Discussion}

According to some authors, the yield of the cultivated crops is greatly influenced by the surface of the plants nutrition, which in turn depends on the quality of seed dosing during seeding [21].

The goal of the research [22] by Nesmiyan is the development of a mechanical and mathematical model that allows predicting the probability of the "zero" seed supply formation by a pneumatic seeding device, depending on the physical and mechanical properties of seeds, the device parameters and operating modes.

Using mathematical expressions, specifying the maximum and minimum values of sizes and masses of seeds, their laying angles, the degree of overlapping of suction holes by seeds, air suction coefficients and angular speed of the seeding disc, the author [22] found the values of maximum and minimum dimensionless coefficients of the zero seed supply probability by dosing elements of the device.

The dependencies of the calculated probability, constructed with mathematical expressions $(a)$ and the frequency of zero seed supply formation by the angular speed of the seeding disc, when dosing maize seeds $(b)$ [22] are presented graphically in Fig. 6.

The obtained dependencies allowed Nesmiyan to establish the fact that it is not advisable to increase the angular speed of the seeding disc above 5.0 $\mathrm{rad} / \mathrm{s}$, since the probability of the "zero" seed supply formation exceeds the allowable values $(2 \%)$, regulated by agrotechnical requirements.

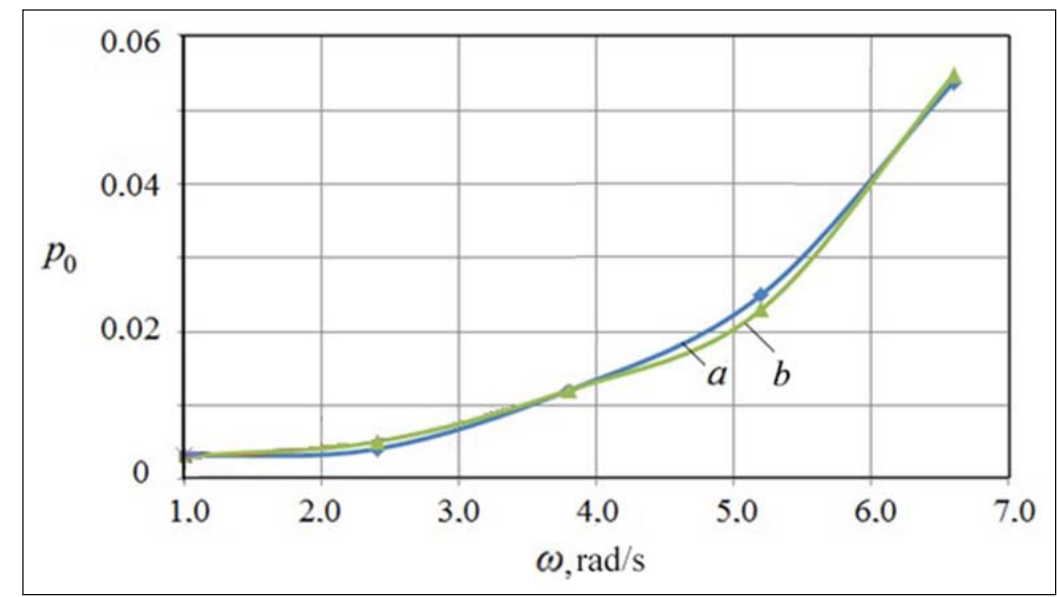

Fig. 6. The probability of the zero seed supply formation, while planting maize seeds, depending on the angular speed of the seeding disc. $a$ - calculated dependence; $b$ - experimental frequency; $p_{0}$ - the probability of the zero seed supply formation; $\omega$ - the angular speed of the seeding disc, $\mathrm{rad} / \mathrm{s}$ 
However, for cucurbit crops it is possible to get minimal zero seed supply by seed cells, but at the same time, the nutritional area for plants will not be provided in accordance with agrotechnical requirements, since the field germination of seeds will make its own corrections.

Therefore, we suggest that seed sowing with field germination of less than $90 \%$ should be produced in bunches in order to ensure optimal feeding area for plants. For this purpose, we propose the design of seeding discs for bunch planting of cucurbits seeds, as well as calculated dependencies to determine the optimal operating modes of the seeding device.

To predict the seeding rate with a known field germination, expressions are proposed to determine the probability of bunches with different numbers of plants in them. Similar dependencies can be proposed for planting any number of seeds in the bunch from one to $n$. The variation curves graphs of the plants distribution in bunches under field conditions and by theoretical calculations for bunch planting of seeds and a certain field germination give a clear idea of the quality of seeding and the further development of the sown culture.

\section{Conclusion}

Complex theoretical studies of the bunch planting process carried out on the basis of its step-by-step analysis, taking into account the developed system of physical models and the phenomena occurring in the seed, allowed us to predict the operational mode of the pneumatic seeding device for bunch planting and to calculate its main parameters.

The dependencies were proposed, which make it possible to determine the required number of the sown seeds in a bunch, taking into account their germination and in full compliance with agrotechnical requirements.

The reliability of theoretical assumptions is confirmed by the results of engineering calculations and experimental studies in the field, which allows us to offer a dosing system that provides high quality bunch planting of watermelon seeds with a given seeding rate and their uniform distribution over the sowing area.

Application of the proposed design of the seeding discs for bunch planting of cucurbit seeds (watermelons, melons, pumpkins and others) with seeders equipped with pneumatic device can increase the operational performance of the seeder, and the friendly germination of seeds due to the easy joint destruction of the soil crust will significantly increase the yield of the sown crops.

\section{Conflict of interest}

The authors declare no conflict of interest. 


\section{Acknowledgements}

The article was published at the expense of the Federal State Budget Institution "Fund for the Promotion of the Development of Small Forms of Enterprises in the Scientific and Technical Field".

\section{References}

[1] Valianov, D. G. (1949) The results of the work on the pneumatic seeding device of continuous action. Reports Collection of the Moscow Timiryazev Agricultural Academy 11: 79-84.

[2] Budagov, A. A., et al. (1970) New pneumatic seeders and seeding sections. Research Collection of the State Kuban Agrarian University 30: 33-27.

[3] Abezin, V. G., et al. (1974) Mechanization of pumpkin crops sowing. Potatoes and vegetables 2: 31-32.

[4] Semenov, V. F. (1964) Investigation of the factors determining the distribution of seeds in the furrow with precise seeding. Materials of Scientific and Technical Council of the All-Union Research Institute of Agricultural Engineering 16: 133-146.

[5] Lobachevsky, P. Y. (1970) Method of identifying patterns of seeding basing on seedlings. Methods of studying the mechanization processes in agriculture. In: All-Russian Research Institute of Mechanization and Electrification of Agriculture, Vol. 2, pp. 161-165. Rostov: Rostov book publ.

[6] Bespamyatnova, N. M. (1986) About the prospects of the sowing intensification. Collection of works, Improvement of technical means and technological processes in field cultivation. All-Russian Research, Design and Technological Institute of Mechanization and Electrification of Agriculture (VNIPTIMESH), Zernograd, pp. 129-138.

[7] Belik, V. F. (1982) Cucurbits growing. Moscow: Kolos, pp. 123-128.

[8] Bondarenko, P. A. (1986) About the method of determining the optimal conditions for the process of single-grain seeding by the sorghum seeding device SUPN-8. Designing of working parts of tillage, harvesting agricultural machines and devices for feed production. Interuniversity compilation. Rostov-on-Don, pp. 45-52.

[9] Gyachev, L. V. (1968) The movement of granular materials in pipes and tankers. Moscow: Machine building, $184 \mathrm{p}$.

[10] Bogomagkih, V. A. (1973) Theory and design of tankers for granular materials. Rostov-on-Don, $148 \mathrm{p}$.

[11] Buzenkov, G. M., Ma, S. A. (1976) Machines for sowing crops. Moscow: Machine building, pp. 128-147.

[12] Lobachevsky, P. Y. (1964) Theory of the batch seeding process with the square pocket seeder. Collection of scientific and technical works. Proceedings of the Azov Black Sea Institute of Agricultural Mechanization, vol. 18. Moscow: Rosselkhozizdat, pp. 78-95.

[13] Krasnov, I. N., Kravchenko, I. A. (2014) Patterns of the plants distribution after bunch planting with a cucurbits seeder. News of universities, North-Caucasian region. Natural sciences 5: 68-71. 
[14] Korogodov, N. S. (1971) The study and selection of optimal modes for seed placement of the accurate sowing, using probabilistic assessment methods. The optimal design of agricultural production processes. Moscow, pp. 140-155.

[15] Tanashev, F. G. (1957) About the number of plants in the bunch. Corn 4: 47-52.

[16] Kravchenko, I. A. (1982) The study of the watermelon seeds sowing process by the seeding device SBN-3 of the cucurbits seeder. Interuniversity collection, Integrated mechanization and automatization of agricultural production. Rostov-on-Don: Institute of agricultural machine building.

[17] Kravchenko, I. A. (1989) Characteristics of the watermelon seed supply by disc cells. Interuniversity collection, Improvement of technological processes and design of agricultural machines. Works of Kuban Agrarian University, no. 294. Krasnodar.

[18] Production and sale of agricultural machinery. Official site of OAO Millerovoselmash. Retrieved from: https://www.millerovoselmash.ru/product/seyalka-pnevmaticheskaya-tochnogo-vyseva-ms-8/.

[19] Kravchenko, I. A. (1992) Intensification of the watermelon seeds sowing technological process with the cucurbits seeder. PhD Dissertation. Zernograd.

[20] Vedenyapin, G. V. (1965) General methods of experimental research and processing of experimental data. Moscow: Kolos, $135 \mathrm{p}$.

[21] Nesmiyan, A. Y., Khizhnyak, V. I., Dolzhikov, V. V., Yakovets, A. V., Shapovalov, D. E. (2013) Optimization of pneumatic seeding devices for seeder: monograph. Zernograd: Federal State Budget Educational Institution of Higher Professional Education Azovo-Chernomorskiy State Agrarian and Engineer Academy, 186 p.

[22] Nesmiyan, A. Y. (2016) Modeling the process of seed dosing of tilled crops with a pneumatic-vacuum seeder of precise sowing. The Buryat State Agricultural Academy named after Filippov V. R. Reporter 3 (44): 117-125. 